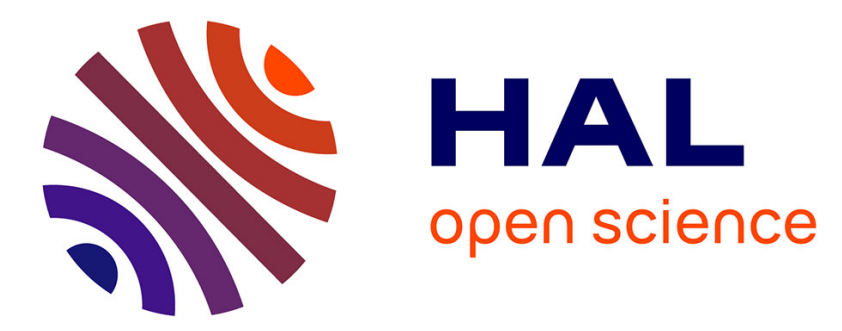

\title{
Influence of grading on undrained behavior of granular materials
}

\author{
Yingjing Liu, Gang Li, Zhenyu Yin, Christophe Dano, Pierre-Yves Hicher, \\ Jian-Hua Wang, Xiao-He Xia
}

\section{- To cite this version:}

Yingjing Liu, Gang Li, Zhenyu Yin, Christophe Dano, Pierre-Yves Hicher, et al.. Influence of grading on undrained behavior of granular materials. Comptes Rendus Mécanique, 2014, 342 (2), pp.85-95. 10.1016/j.crme.2013.11.001 . hal-01006972

\section{HAL Id: hal-01006972 \\ https://hal.science/hal-01006972}

Submitted on 28 May 2017

HAL is a multi-disciplinary open access archive for the deposit and dissemination of scientific research documents, whether they are published or not. The documents may come from teaching and research institutions in France or abroad, or from public or private research centers.
L'archive ouverte pluridisciplinaire HAL, est destinée au dépôt et à la diffusion de documents scientifiques de niveau recherche, publiés ou non, émanant des établissements d'enseignement et de recherche français ou étrangers, des laboratoires publics ou privés. 


\title{
Influence of grading on the undrained behavior of granular materials
}

\author{
Ying-Jing Liu ${ }^{a, b}, G$ a $n g^{2} i^{b, d}$, Zhen-Yu Yin ${ }^{a, b}$, Christophe Dano ${ }^{b}$, \\ Pierre-Yves Hicher ${ }^{\text {b,c }}$, Xiao-He Xia ${ }^{a}$, Jian-Hua Wang ${ }^{a}$ \\ a Department of Civil Engineering, Shanghai Jiao Tong University, 200240 Shanghai, China \\ b LUNAM University, École centrale de Nantes, GeM, UMR CNRS 6183, 1, rue Noë, 44300 Nantes, France \\ c College of Civil Engineering, Tongji University, Shanghai, China \\ d CCCC Third Harbor Consultants Co., Ltd., 200032 Shanghai, China
}

Keywords:

Grain size distribution Undrained triaxial test Instability DEM

Relative density

Granular material
Mots-clés:

Étalement granulométrique Essai triaxial non drainés Instabilité

DEM

Densité relative

Matériau granulaire

\section{A B S T R A C T}

This paper aims at investigating the influence of grading on the undrained behavior of granular materials. Series of undrained triaxial tests were carried out with two different materials, glass balls and Hostun sand. For each material, samples with different gradings and similar relative densities were prepared. Experimental results show that the undrained shear strength decreases when the coefficient of uniformity $C_{\mathrm{u}}=d_{60} / d_{10}$ increases from 1.1 to 20. The conditions of instability for the selected granular materials were also analyzed, based on the sign of the second-order work during undrained triaxial loading. The results demonstrate a significant influence of the grading: increasing the coefficient of uniformity heightens the potential of static liquefaction and the materials become more unstable. Furthermore, numerical tests using the three-dimensional discrete element method (DEM) were conducted on assemblies of spheres. The DEM inter-particle parameters were derived from the experimental test results on glass balls. The DEM simulations showed similar behaviors compared to experimental results and confirmed the influence of the grain size distribution on the stress-strain relationship and instability phenomena.

\section{R É S U M É}

Cet article vise à étudier l'influence de l'étalement granulométrique sur le comportement non drainé des matériaux granulaires. Des séries d'essais triaxiaux non drainés ont été réalisés sur deux matériaux différents, des billes de verre et du sable Hostun. Pour chaque matériau, des échantillons de différentes granulométries et de densités relatives similaires ont été préparés. Les résultats expérimentaux montrent que la résistance au cisaillement diminue lorsque le coefficient d'uniformité $C_{\mathrm{u}}=d_{60} / d_{10}$ augmente de 1,1 à 20. Les conditions d'instabilité pour les matériaux granulaires sélectionnés ont également été analysées, sur la base du signe du travail du second ordre au cours d'un chargement triaxial non drainé. Les résultats montrent une influence significative de l'étalement granulométrique : l'augmentation du coefficient d'uniformité accroît le potentiel de liquéfaction statique et les matériaux deviennent plus instables. En outre, des essais numériques en utilisant la méthode des éléments discrets en trois dimensions (DEM) ont été effectués sur des assemblages de sphères. Les paramètres inter-particules DEM ont été calculés à partir des résultats d'essais expérimentaux sur des billes de verre. Les simulations DEM ont montré des comportements similaires comparés aux résultats expérimentaux et confirment l'influence de l'étalement granulométrique sur la relation contrainte-déformation et les phénomènes d'instabilité. 


\section{Introduction}

Certain mechanical characteristics of granular materials under undrained condition, such as shear strength and instability, are of great importance in geotechnical engineering. A poor assessment of these factors may lead to catastrophic disasters such as gross collapses of civil engineering structures under rapid loading. Concerning the undrained shear strength of granular materials, the affecting factors have been extensively studied [1-9]. However, in most of these studies, the influence of the grain size distribution was mixed with other factors such as mean grain size, particle shape, etc. Granular materials with high coefficients of uniformity are not very commonly tested and required further investigations.

In undrained condition, granular materials are known to become unstable even before their stress states reach the failure state (see, for example, [10-15]). The term instability generally refers to a behavior in which large plastic strains can be rapidly generated owing to the inability of a soil element to sustain a given even small additional load. It is generally accepted that the second-order work theory postulated by Hill $[16,17]$ can be used as a stability criterion, the material being potentially unstable if the sign of the second order work becomes negative at a given mechanical state. If this condition is reached, it does not always imply that failure would occur, as experimentally demonstrated by Lade and Pradel [18]. The directions of the incremental load as well as the mechanical variables controlling this incremental load are of major importance. Therefore, Hill's postulation is only a necessary, but not a sufficient condition for instability [14]. These findings were established mainly on poorly graded loose granular materials. However, very limited studies have focused on the influence of the grain size distribution on the instability potential.

Therefore, evaluating the grading influence on undrained behavior of granular materials is the main focus of this study. For this purpose, two granular materials, Hostun sand and glass balls were selected. For each material, a series of undrained triaxial tests on samples with different gradings but similar relative densities were carried out. Based on test results, the influence of the grading on the undrained behavior is discussed. Furthermore, numerical triaxial tests by means of the three-dimensional discrete elements method (DEM) were carried out on spheres assemblies with different gradings in order to complement the experimental results.

\section{Experimental program}

\subsection{Tested materials}

As discussed above, several factors may influence the undrained behavior of granular materials. Therefore, studying this topic without separating the affecting factors (grading, mean grain size, particle shape, etc.) would inevitably reduce the significance of the findings. For example, few studies have analyzed the tested material shapes, while even for the same material the particle shape is not always the same for different grain sizes [19]. It has been found that increasing the particle angularity leads to an increase in the void ratios index $e_{\max }$ (maximum void ratio) and $e_{\min }$ (minimum void ratio) [20], a decrease in stiffness and an increase in critical state friction angle $\phi_{\mathrm{cs}}$ [21]. It has also been found that the particle shape effect on the liquefaction susceptibility is significant [22]. Therefore, in order to highlight the grading influence on the undrained behavior of granular materials, the tested materials should have similar particle shape over the full selected size range. Along this way, we tried to prepare materials with similar particle shape and same specific gravity for different grain sizes. The grading curves retained for this study are shown in Fig. 1 , where the main grain size $d_{50}$ is kept almost identical to $0.9 \mathrm{~mm}$ and $C_{\mathrm{u}}=d_{60} / d_{10}$ varies from 1.1 to 20 . For each specimen, the total solid mass for the required void ratio is calculated. Given the targeted grading curve, the percentage of each range corresponding to a given sieve (for example $0.08-0.1 \mathrm{~mm}$ ) can be calculated, then the required mass of the grains in all the different ranges are determined and the specimen is prepared by mixing all these grains with different sizes.

For glass balls, as they are artificially manufactured, particle shapes are very similar from one given size to another, whereas Hostun sand being a grinded material, the similarity of the particles shape should be analyzed before testing. Particle shape analyses were performed based on the Scanning Electron Microscope (SEM) observations. The similarities of Hostun sand grains with different sizes were quantified by the shape parameter $\beta$ [23]:

$$
\beta=L_{\mathrm{M}} / / L_{\mathrm{m}}
$$

where $L_{\mathrm{M}}$ and $L_{\mathrm{m}}$ are the major and minor lengths of the minimum circumscribed rectangular (in 2D), respectively. The particle shape analysis is mainly divided into two processes: the imaging procedure (to obtain the value of $\beta$ of each particle) and the mathematical statistical process.

The imaging procedure consists of the following three steps (see Fig. 2): (1) an image of particles was obtained by SEM imaging; (2) the binaryzation treatment was performed on this image using the built-in box in Matlab; (3) $L_{\mathrm{M}}$ and $L_{\mathrm{m}}$ of the particles were determined by using the open software ImagJ. 


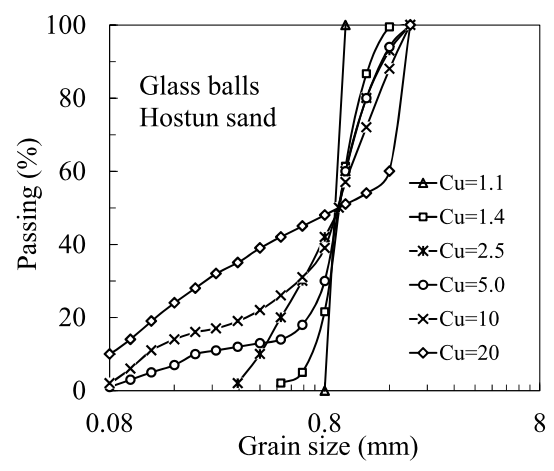

Fig. 1. Grain size distributions for all tested samples.

(a)

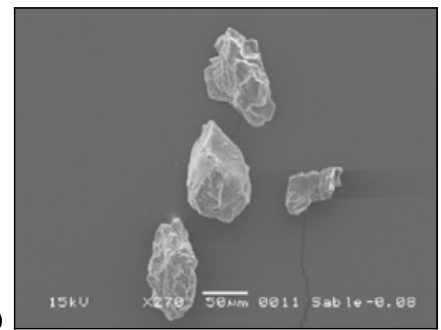

(b)

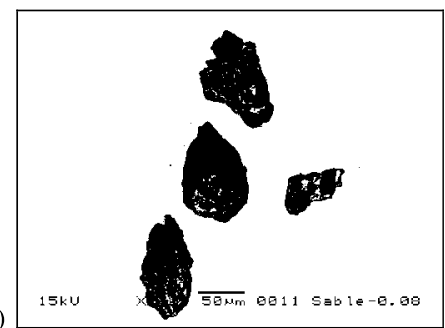

(c)

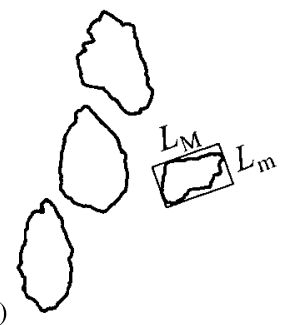

Fig. 2. Digital image processing: (a) SEM image; (b) binaryzation; (c) boundary extraction.

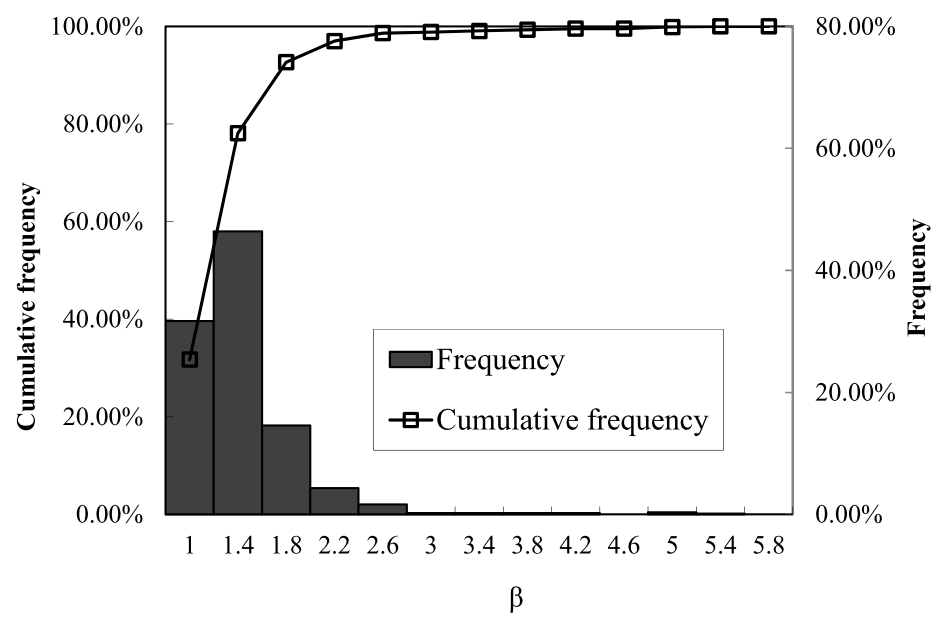

Fig. 3. Histogram of the particle shape analysis.

The statistical process was performed by using Excel and the results of the particle shape analysis with grain diameters from $0.08 \mathrm{~mm}$ to $2 \mathrm{~mm}$ (860 particles) are presented in Fig. 3. It was found that: the shape parameter $\beta$ varies mainly from 1.0 to 1.4 , corresponding to the accumulated frequency range up to $80 \%$. Therefore, the shape of Hostun sand grains in the selected diameter range can be regarded as similar, which meets the study's requirement.

The variation of $e_{\max }$ and $e_{\min }$ measured with the ASTM standard [24,25] versus the grading is given in Fig. 4. As it can be observed, the relationship between $e_{\max }$ or $e_{\min }$ and the coefficient of uniformity $C_{\mathrm{u}}$ can be expressed by an exponential function, $e_{\max }$ and $e_{\min }$ decreasing with the increase of $C_{\mathrm{u}}$, down to almost constant values for $C_{\mathrm{u}}$ higher than 10 , similar to the correlations reported by Biarez and Hicher [20].

\subsection{Testing program}

Twelve conventional triaxial tests under undrained condition were performed on the selected materials. For each material, one specimen (100 mm in diameter and $200 \mathrm{~mm}$ in height) was prepared for each grading. The compaction method [9] was used to prepare the specimens in relatively homogeneous condition. In order to prepare a specimen with a desired 

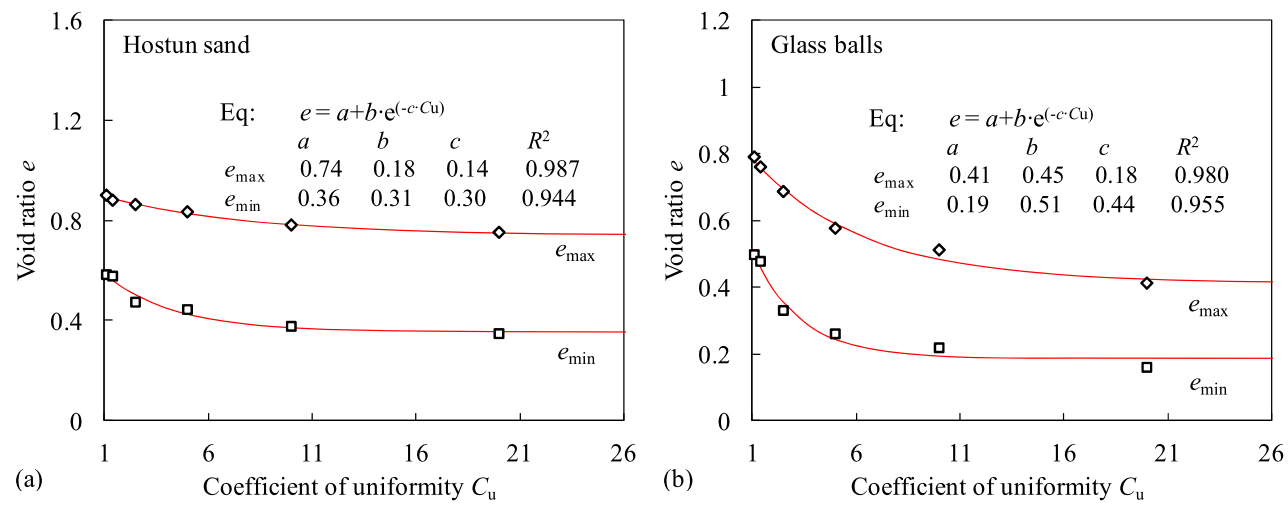

Fig. 4. Evolution of index void ratios $\left(e_{\max }, e_{\min }\right)$ with the coefficient of uniformity $C_{\mathrm{u}}$ : (a) Hostun sand; (b) glass balls.

Table 1

Initial void ratios and relative densities for selected materials.

\begin{tabular}{|c|c|c|c|c|}
\hline \multirow[t]{2}{*}{ Grading } & \multicolumn{2}{|c|}{ Hostun sand } & \multicolumn{2}{|c|}{ Glass balls } \\
\hline & $e_{0}$ & $D_{\mathrm{r}}$ & $e_{0}$ & $D_{\mathrm{r}}$ \\
\hline$C_{\mathrm{u}}=1.1$ & 0.764 & $42.9 \%$ & 0.660 & $43.1 \%$ \\
\hline$C_{\mathrm{u}}=1.4$ & 0.753 & $42.1 \%$ & 0.635 & $42.4 \%$ \\
\hline$C_{\mathrm{u}}=2.5$ & 0.698 & $42.3 \%$ & 0.539 & $41.4 \%$ \\
\hline$C_{\mathrm{u}}=5.0$ & 0.670 & $42.2 \%$ & 0.443 & $42.3 \%$ \\
\hline$C_{\mathrm{u}}=10$ & 0.612 & $41.3 \%$ & 0.393 & $41.9 \%$ \\
\hline$C_{\mathrm{u}}=20$ & 0.585 & $41.4 \%$ & 0.317 & $42.4 \%$ \\
\hline
\end{tabular}

relative density $D_{\mathrm{r}}=\left(e_{\max }-e\right) /\left(e_{\max }-e_{\min }\right)=42 \%$, each specimen was prepared by first estimating its dry weight. After the specimen was formed, the specimen cap was placed, then a vacuum of 10-20 kPa was applied and the mould was dismantled. The sample was then saturated until Skempton's B parameter became higher than 0.97 , and then isotropically consolidated at a constant effective stress before undrained compression.

The initial void ratios and relative densities corresponding to the end of the isotropic loading phase are listed in Table 1 for each specimen. Note that the initial void ratio $e_{0}$ was measured using the conventional method (measuring specimen height, diameter, mass, and specific gravity), which has $5-10 \%$ difference with the values obtained by using the water content method [26].

All undrained triaxial tests were carried out at a constant strain rate of $0.15 \% / \mathrm{min}$, which is slow enough to allow pore pressure changes to equalize throughout the sample. No anti-fretting device was used in the testing. As the end restraint, membrane penetration, sample size effects, etc. could not be ignored in conventional triaxial testing, it is widely accepted that the test data for axial strains higher than $20 \%$ are not reliable; thus in this study all the tests were conducted only up to an axial strain of $20 \%$.

\subsection{Test results and analyses}

(i) Hostun sand

Fig. 5 shows the results of undrained triaxial tests on samples of Hostun sand under the effective confining stress of $100 \mathrm{kPa}$ with $C_{\mathrm{u}}$ varying from 1.1 to 20. From Fig. 5(a), the increase of the coefficient of uniformity $C_{\mathrm{u}}$ induces a decrease of the deviatoric stress throughout the entire loading. This decrease may result from the role of the small size particles in increasing the contractiveness of the sample for a given relative density, which leads to an increase of the excess pore pressure and consequently to a decrease of the undrained strength. Indeed, DEM simulations have shown that external loads are transferred through the granular structure by force chains. In mono disperse granular materials, the collapse and reconstitution of the force chains during continuous loading do not lead to significant reorganization of the structure, whereas for poly disperse material, the reorganization among particles of different sizes is more pronounced, leading to higher contractancy of initially loose packing.

Fig. 5(b) shows that the material exhibits more contractive behavior with higher $C_{\mathrm{u}}$ values, leading to a higher increase of the pore pressure (decrease of the mean effective stress) during the first stage of the triaxial loading. This pore pressure increase can be sufficiently high to lead to a so-called static liquefaction of the specimen. This is the case for the high $C_{\mathrm{u}}$ values. This decrease in the deviatoric stress is only temporary and stops when the characteristic state (or phase transformation state) is reached. Then, in the second phase of the loading the pore pressure decreases continuously and the stress path follows all the way up the characteristic line until the critical state is eventually reached. 


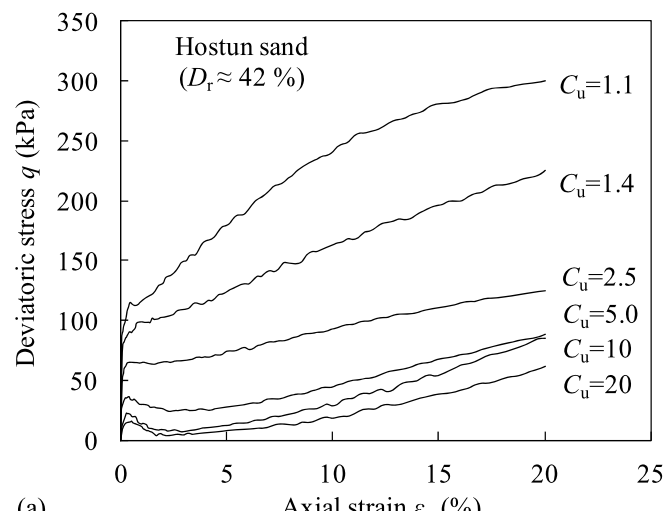

(a)

Axial strain $\varepsilon_{\mathrm{a}}(\%)$

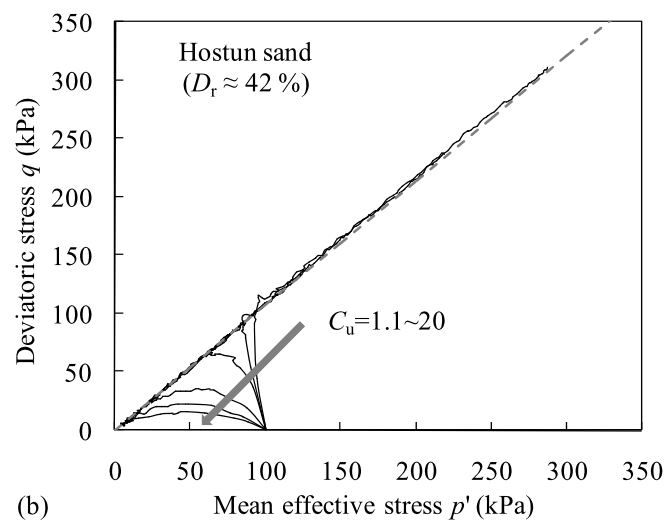

Fig. 5. Undrained stress-strain responses of Hostun sand specimens with different gradings: (a) deviatoric stress versus axial strain; (b) deviatoric stress versus mean effective stress.

(ii) Glass balls

Similar trend was also found in undrained triaxial tests on glass balls, see Fig. 6. For glass balls, under a low initial confining stress (for example $p_{0}^{\prime}=100 \mathrm{kPa}$ ), the stick-slip phenomenon is very pronounced, and the noising data has a prominent influence on the data analysis. Because increasing the confining stress can reduce the stick-slip phenomenon, all the glass balls samples were loaded under a relatively high confining stress $p_{0}^{\prime}=400 \mathrm{kPa}$.

(iii) Undrained shear strength

We define the deviatoric stress corresponding to an axial strain of $20 \%\left(q_{20 \%}\right)$ to be the undrained shear strength $q_{\mathrm{s}}$. For glass balls (Fig. 6(a)), it is found that all the samples reached an almost stable state at strain level around $20 \%$. For Hostun sand (Fig. 5(a)), the deviatoric stress is still increasing until the end of the loading and therefore its value for an axial strain equal to $20 \%$ cannot be considered as the maximum undrained strength. Nevertheless, for the sake of examining the influence of $C_{\mathrm{u}}$ on the undrained shear strength, we plotted the evolution of $q_{20 \%}$ with $C_{\mathrm{u}}$ for both materials as shown in Fig. 7. The undrained shear strength $q_{\mathrm{s}}$ decreases as the coefficient of uniformity $C_{\mathrm{u}}$ increases. This result implies that when a higher $C_{\mathrm{u}}$ is induced by grain breakage for instance, the undrained shear strength of soil decreases.

(iv) Phase transformation state

As shown in Figs. 5 and 6, when granular materials are sheared under undrained condition, they often exhibit the so-called phase transformation state [27] or characteristic state [28], corresponding to the transition between contractive and dilative behavior. For both materials, it was found that the grading affects significantly the value of the deviatoric stress at the phase transformation state $q_{\mathrm{pt}}$, as shown in Fig. 8: with the increase of $C_{\mathrm{u}}, q_{\mathrm{pt}}$ decreases. An exponential function was used to fit this relation which agrees with the fact that, when $C_{\mathrm{u}}$ becomes higher than 10 , $q_{\mathrm{pt}}$ tends to become stable.

(v) Undrained instability

In order to investigate the instability criterion in undrained condition, the second-order work was calculated for each test. According to Hill [17], stability is guaranteed if the second-order work is strictly positive. Otherwise, whenever it vanishes or becomes negative, there is a potential for material instability. The second-order work for conventional axisymmetric triaxial tests can be expressed as:

$$
\mathrm{d}^{2} w=\mathrm{d} p^{\prime} \mathrm{d} \varepsilon_{v}+\mathrm{d} q \mathrm{~d} \varepsilon_{d}
$$

Under undrained triaxial condition, the volumetric strain increment $\mathrm{d} \varepsilon_{\mathrm{v}}=0$ and the deviatoric strain increment $\mathrm{d} \varepsilon_{\mathrm{d}}=\mathrm{d} \varepsilon_{\mathrm{a}}, \varepsilon_{\mathrm{a}}$ being the axial strain. The second-order work expression is reduced to $\mathrm{d}^{2} w=\mathrm{d} q \mathrm{~d} \varepsilon_{\mathrm{a}}$. Since the axial strain 

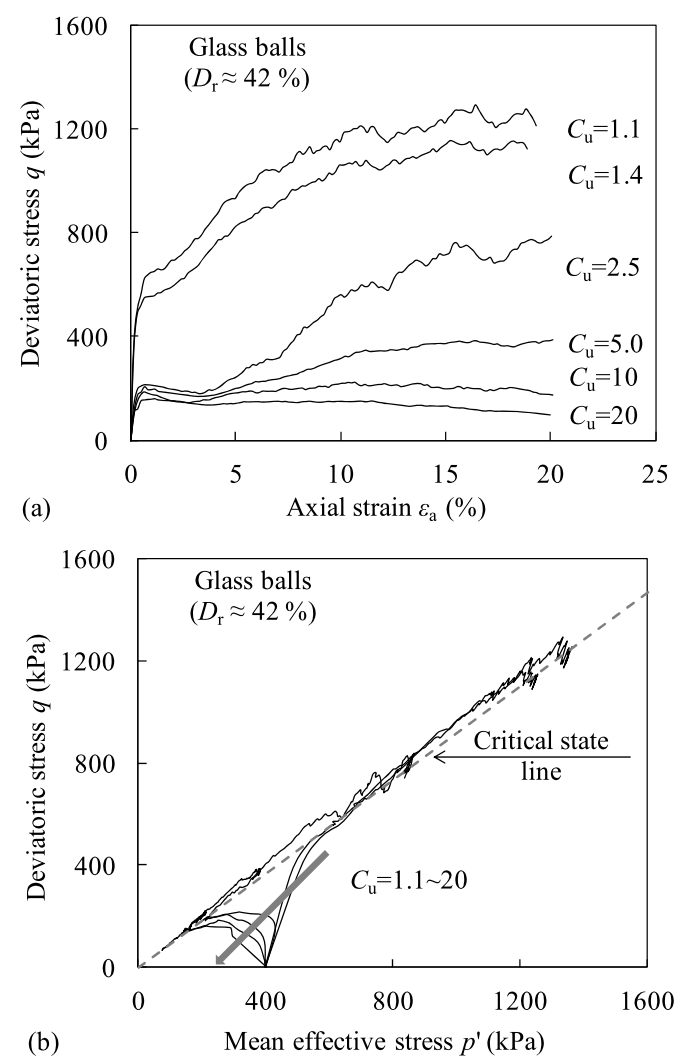

Fig. 6. Undrained stress-strain responses of glass balls specimens with different gradings: (a) deviatoric stress versus axial strain; (b) deviatoric stress versus mean effective stress.
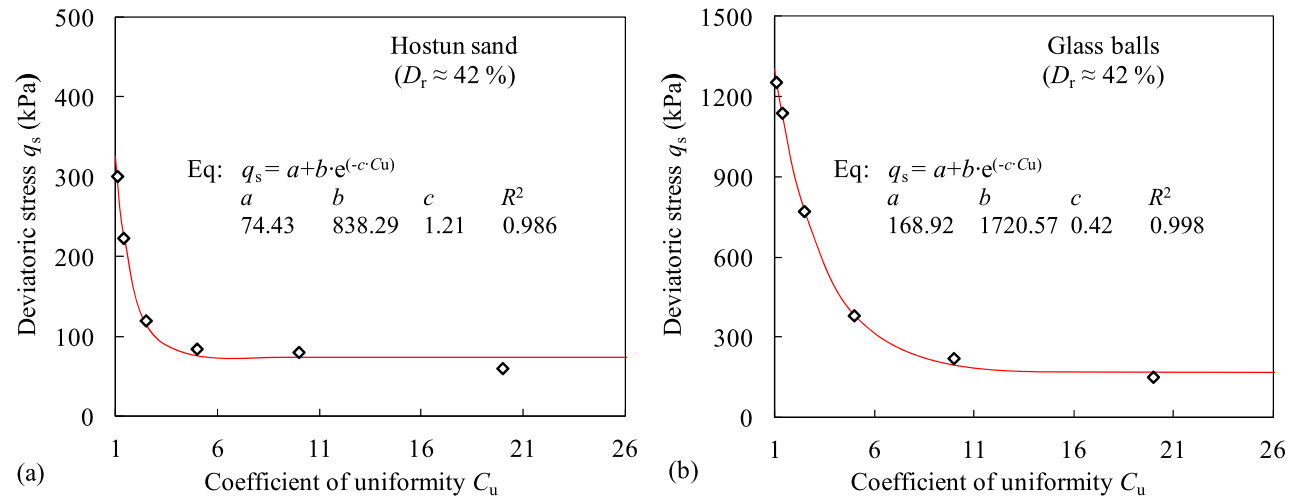

Fig. 7. Relationship between shear strength and coefficient of uniformity: (a) Hostun sand; (b) glass balls.

continuously increases in the conventional undrained triaxial tests, the second-order work becomes non-positive if and only if $\mathrm{d} q \leqslant 0$ (i.e., decrease in $q$ ).

As shown in Fig. 9, with the increase of the coefficient of uniformity $C_{u}$, negative values of the second-order work appear earlier in terms of strain amplitudes. For samples with higher $C_{\mathrm{u}}\left(C_{\mathrm{u}}=2.5,5.0,10,20\right)$, the second-order work becomes negative after the first peak of the deviatoric stress, whereas for samples with lower $C_{u}\left(C_{u}=1.1,1.4\right)$ the second-order work remains always positive. These results show that a broader grading enhances the potential of static liquefaction.

\section{Numerical tests on idealized granular materials}

In order to further verify the experimental findings, numerical tests were carried out by DEM simulations. Although, in recent years, DEM has been used to simulate the grading effect of granular materials [29,30], complementary studies are still needed. 

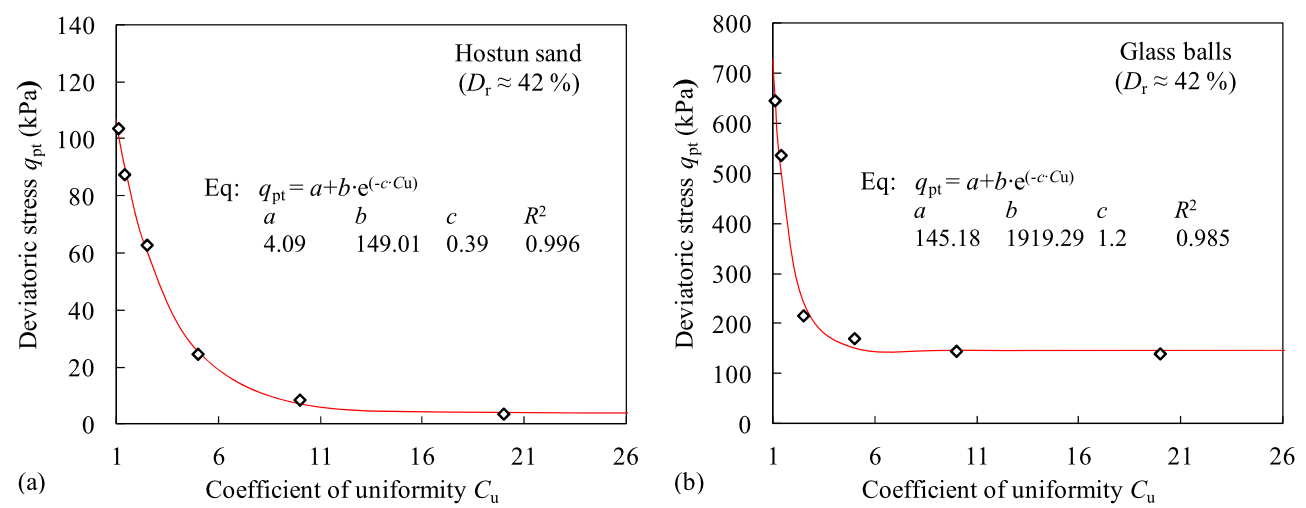

Fig. 8. Relationship between phase transformation state deviatoric stress and coefficient of uniformity: (a) Hostun sand; (b) glass ball.
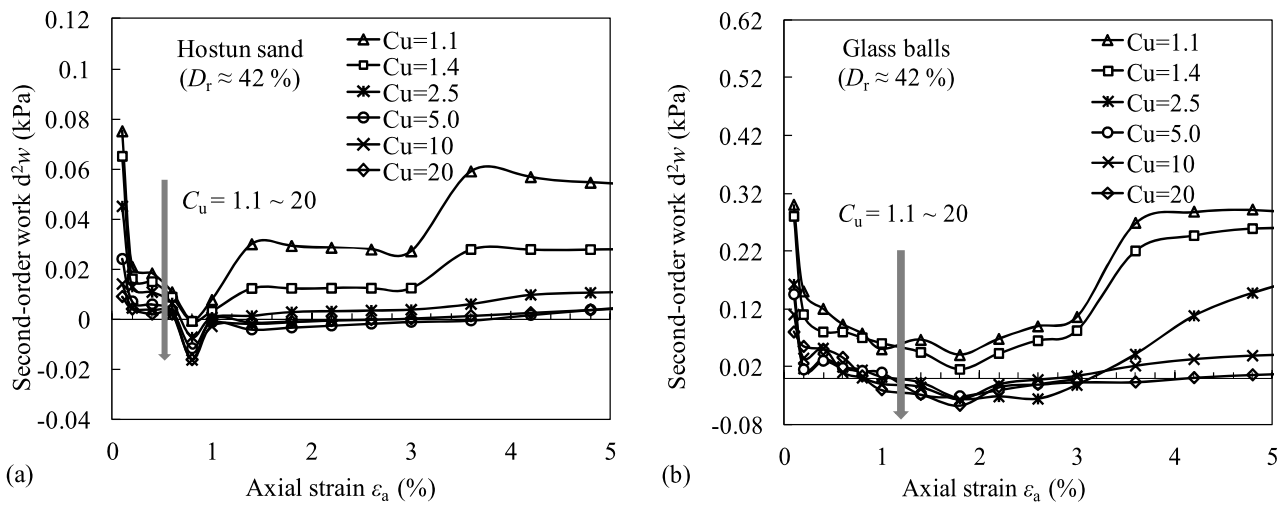

Fig. 9. Evolution of second-order work in undrained testing: (a) Hostun sand; (b) glass balls.

In experimental soil mechanics, the determination of the minimum and maximum void ratios is important, and relative density is often used as a unifying measure for comparing the mechanical responses of various granular materials. Many experimental methods have been developed to measure $e_{\max }$ and $e_{\min }$ for granular materials, but there has been little exploration of techniques for generating numerical (e.g. DEM) samples at maximum and minimum void ratios [31]. Muir Wood and Maeda [29] generated 2D samples at a void ratio equal to $e_{\max }$ by setting the friction angle between disks to be $45^{\circ}$ during the initial compression, whereas setting the friction angle to be $0^{\circ}$ to generate samples at $e_{\text {min }}$. However, $e_{\max }$ and $e_{\text {min }}$ generated by such numerical methods do not have much in common with the values measured in the laboratory by a normalized method [24,25]. Therefore, the calculated relative densities of the numerical samples would not reflect the real soil state. In this study, in order to fix the relative density of samples with different gradings and highlight the grading effect on the undrained shear strength and instability of granular materials, an indirect method to produce 3D DEM samples at the same relative density as the tested glass balls was used.

\subsection{Index void ratios of DEM samples}

We need heavy computation time in DEM simulations to analyze $e_{\max }$ and $e_{\min }$ of a given granular material, especially for materials with high values of $C_{\mathrm{u}}$.

The factors affecting $e_{\max }$ and $e_{\min }$ have been extensively studied by Biarez and Hicher [20], Cubrinovski and Ishihara [32], and Cho et al. [21]. The affecting factors could be summarized as follows: grading, particle shape (angularity, roundness, etc.), mineral composition, specific gravity.

Therefore, it can be assumed that the index void ratios $e_{\max }$ and $e_{\min }$ obtained experimentally on glass balls samples will be the same for DEM samples made of spheres with the same particle shape and the same inter-particle properties as the tested glass balls, and having the same grading. Then, what is needed is to find the inter-particle properties of the DEM spheres which will give similar stress-strain properties as the glass balls samples at the same void ratio and same grading.

\subsection{Specimen creation and parameters determination based on glass balls}

The DEM numerical analyses were performed using PFC3D software. The contact law for particle interaction is a simple combination of linear springs and limiting friction. A specimen made of spheres was first generated with a specified number 


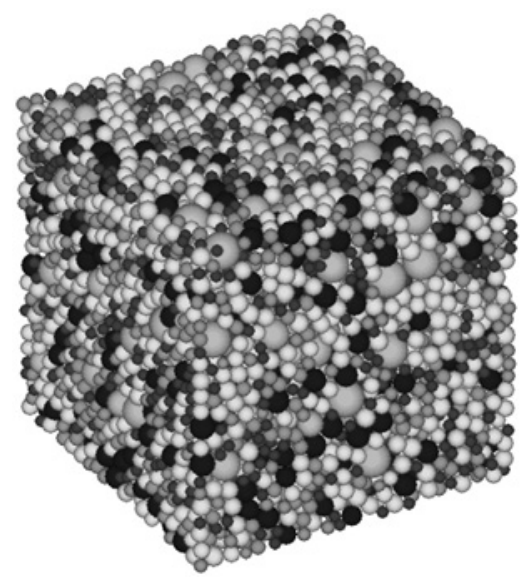

Fig. 10. Representative volume element for DEM simulation (walls are not shown).

of particles within a cubic container without overlap before applying a radius expansion to the spheres up to a specified value in order to obtain the predetermined void ratio of the specimen.

The boundaries of the samples were defined by "wall" elements (walls are not shown in Fig. 10), through which displacement rates can be imposed upon the specimen by controlling the movement of the walls. The required numbers of spheres for a given grading were placed randomly in the container enclosed by six walls. The spheres were then expanded to their final size and the system was run to equilibrium until the ratio of the maximum unbalance force to the mean contact force became smaller than a set tolerance value (e.g., $10^{-3}$ ). A damping ratio of 0.628 [33] was used in this study to accelerate the equilibrium process. In this study, the tests were simulated under zero gravity condition.

The samples were loaded by moving the six walls inwards and brought to an initial isotropic stress. The top and bottom walls are loading platens and the four lateral walls provide confinement. A stress-controlled mode was used through a servo-control mechanism by adjusting the boundary wall movements. The stress was estimated from the summation of all contact forces acting on a parallel pair of walls, divided by the current function area of the walls. All the stress components were determined.

For the undrained test, after isotropic compression, the specimen was compressed in the vertical direction in a straincontrolled mode by specifying a strain rate of $0.03 / \mathrm{s}$ of the top and bottom walls, whereas the volume of the sample was kept constant by specifying the strain-rate of the lateral walls. For drained test, after isotropic compression, the specimen was compressed in the vertical direction in a strain-controlled mode by specifying a strain rate of $0.03 / \mathrm{s}$ of the top and bottom walls. The horizontal stress was maintained constant by continuously adjusting the width and length of the assembly as the vertical compression proceeded.

In order to calibrate the DEM model, two experimental results were used: one drained and one undrained triaxial tests under a confining pressure of $400 \mathrm{kPa}$ on samples of glass balls with $C_{\mathrm{u}}=1.1$. The DEM simulations were performed under the same loading condition and the same initial void ratio (see Table 2). The inter-particle parameters friction coefficient $\mu=0.453$, normal contact stiffness $k_{\mathrm{n}}=3.0 \times 10^{7} \mathrm{~N} / \mathrm{m}$ and tangential contact stiffness $k_{\mathrm{s}}=1.0 \times 10^{7} \mathrm{~N} / \mathrm{m}$ were obtained by fitting the stress-strain curves by minimizing the overall distance between the DEM fitting curves and the experimental curves, shown in Fig. 11. No shear band detected for all simulation at large shear strains. Note that due to some factors (soft or rigid boundary, sample preparation, etc.), there are still small differences between the results of DEM simulation and the experiment data for the undrained triaxial test but with a same set of parameters DEM simulations can have a good catch of the evolution trend of the mechanical behavior of the studied materials.

\subsection{Numerical tests}

Three other samples with three different gradings $\left(C_{\mathrm{u}}=1.4,2.5\right.$ and $\left.5.0, d_{50}=0.9 \mathrm{~mm}\right)$ identical to the ones used in the experimental tests were simulated with the same set of micro parameters $\left(\mu, k_{\mathrm{n}}, k_{\mathrm{s}}\right)$. The details of the numerical tests, including the grading, the sample sizes, the confinement stress $p_{0}^{\prime}$, the void ratios corresponding to $p_{0}^{\prime}$ (close to the void ratios of the glass balls assemblies in experimental testing) and the type of loading drained triaxial compression test (CIDC) and undrained triaxial compression test (CIUC), are listed in Table 2.

\subsection{Analyses of numerical tests}

Fig. 12 shows the undrained stress-strain response of samples with different gradings but the same initial void ratio as the corresponding glass balls assemblies. The initial relative density $\left(D_{\mathrm{r}} \approx 42 \%\right)$ of numerical samples can be regarded as same as samples of glass balls. By comparing Fig. 6 and Fig. 12, one can see that the DEM simulations show similar phenomena as the experiments on glass balls. The undrained shear strength decreases as $C_{\mathrm{u}}$ increases. 

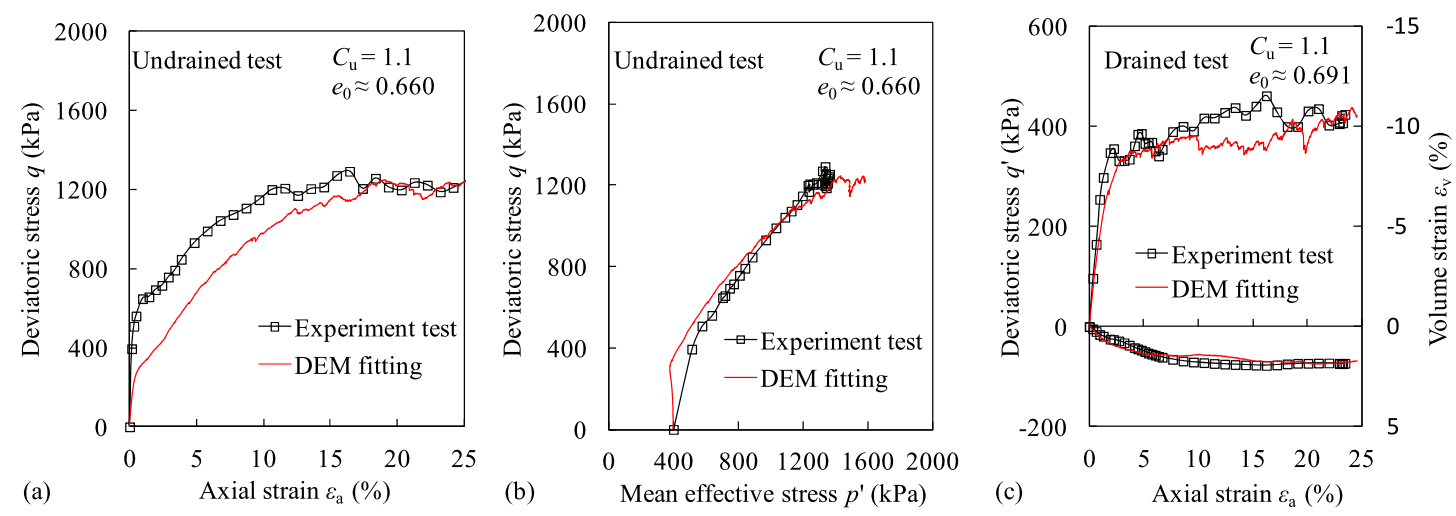

Fig. 11. DEM simulation for glass balls $\left(C_{\mathrm{u}}=1.1\right.$ ): (a) undrained deviatoric stress versus axial strain; (b) undrained deviatoric stress versus mean effective stress; (c) drained deviatoric stress versus volume strain versus axial strain.

Table 2

Details of numerical tests.

\begin{tabular}{|c|c|c|c|c|c|c|}
\hline Test (No.) & $C_{\mathrm{u}}$ & Sample size $/ \mathrm{mm}^{3}$ & Number of particles & $p_{0}^{\prime} / \mathrm{kPa}$ & $e_{0}$ & Type of loading \\
\hline 1 & 1.1 & $12 \times 12 \times 12$ & 2429 & 400 & 0.691 & CIDC \\
\hline 2 & 1.1 & $12 \times 12 \times 12$ & 2429 & 400 & 0.660 & CIUC \\
\hline 3 & 1.4 & $20 \times 20 \times 20$ & 10364 & 400 & 0.635 & CIUC \\
\hline 4 & 2.5 & $16 \times 16 \times 16$ & 18122 & 400 & 0.539 & CIUC \\
\hline 5 & 5.0 & $10 \times 10 \times 10$ & 16417 & 400 & 0.443 & CIUC \\
\hline
\end{tabular}
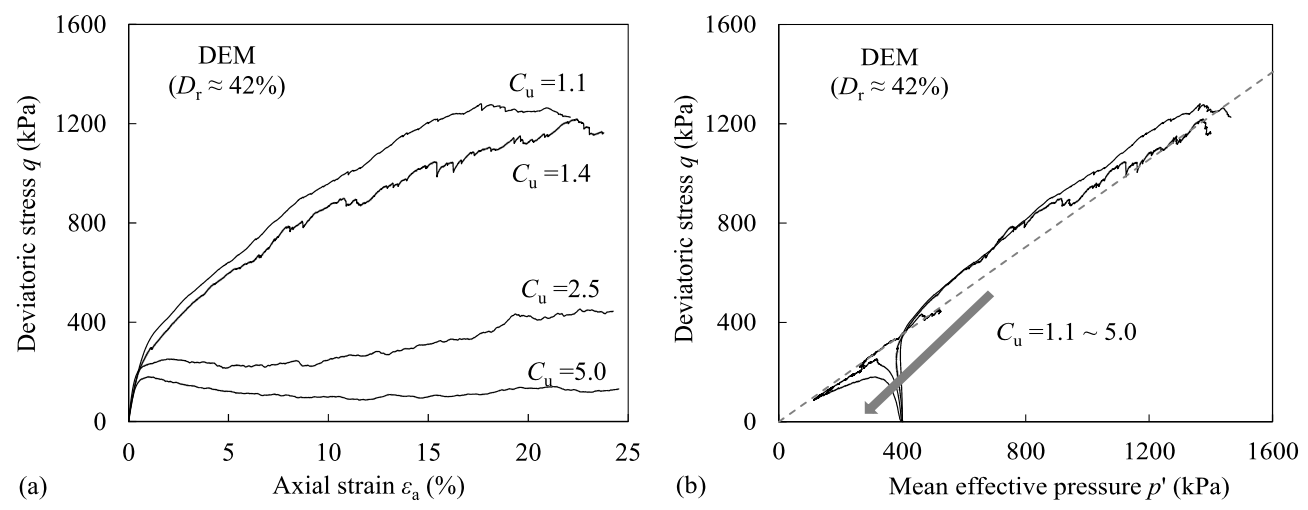

Fig. 12. Undrained stress-strain responses of DEM specimens with different gradings: (a) deviatoric stress versus axial strain; (b) deviatoric stress versus mean effective stress.

In Fig. 13(a) and (b), the undrained shear strength and the phase transformation deviatoric stress are plotted versus the coefficient of uniformity. A trend similar to the one obtained for the glass balls (Figs. 7(b) and 8(b)) is derived. Fig. 13(c) shows the evolution of the second-order work with the axial strain; for samples with high $C_{\mathrm{u}}\left(C_{\mathrm{u}}=2.5\right.$, 5.0) the secondorder work is negative at a strain level of $1-3 \%$, whereas for samples with low $C_{\mathrm{u}}\left(C_{\mathrm{u}}=1.1,1.4\right)$ the second-order work is always positive. These DEM findings agree well with the experiment results. Therefore, the proposed numerical method can be used to reproduce quantitatively the mechanical behavior of granular material.

\section{Conclusions}

Series of undrained triaxial tests on different materials (Hostun sand, glass balls, and idealized sphere packing by DEM) were carried out, for each material on samples with different gradings but similar relative density, in order to investigate the grading effect on the undrained behavior of granular materials. Based on the test results, conclusions can be made as followed.

For samples with the same relative density, the undrained shear strength and the phase transformation deviatoric stress gradually decrease with the increasing coefficient of uniformity $C_{\mathrm{u}}$, and tend to stabilize for $C_{\mathrm{u}}$ higher than 10 . The relationship between the undrained shear strength or the phase transformation deviatoric stress and $C_{\mathrm{u}}$ could be expressed by using an exponential function. 

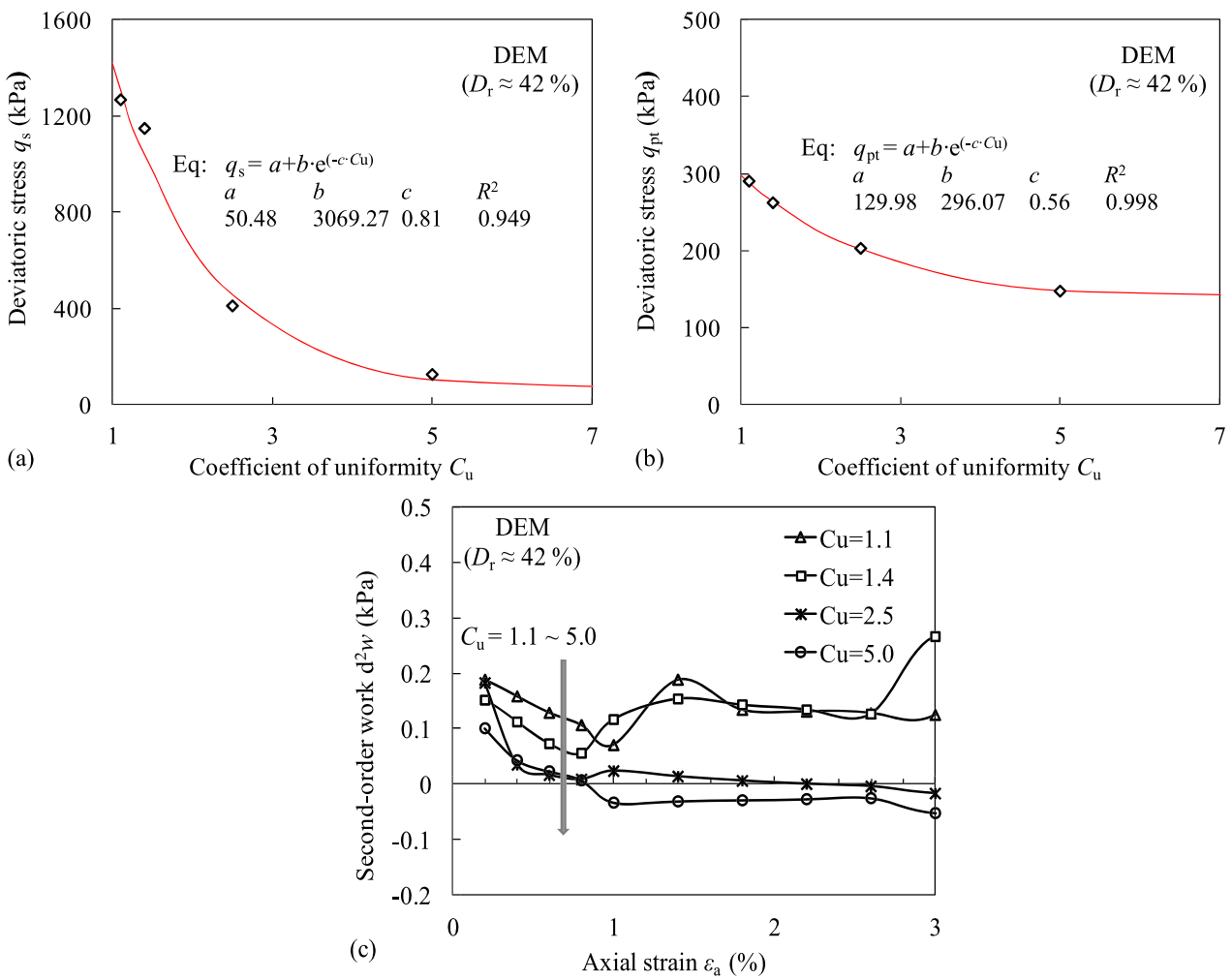

Fig. 13. (a) Undrained shear strength versus the coefficient of uniformity; (b) phase transformation stress versus the coefficient of uniformity; (c) secondorder work versus coefficient of uniformity.

Based on the analyses of the sign of the second-order work, the undrained instability of all selected granular materials was analyzed, demonstrating a significant influence of the grading: increasing the coefficient of uniformity enhances the static liquefaction potential.

Factors which could affect the index void ratios $\left(e_{\max }\right.$ and $\left.e_{\min }\right)$ were summarized and inter-particle parameters of DEM samples were derived from two triaxial tests on glass balls with $C_{\mathrm{u}}=1.1$ by curve fitting. DEM simulations on assemblies of spheres with different grain size distributions revealed similar phenomena concerning the grading influence on the undrained shear strength and the condition of instability compared to experimental results.

\section{Acknowledgements}

We gratefully acknowledge the financial support provided by the Research Fund for the Doctoral Program of Higher Education of China (Grant No. 20110073120012), the China Nation Science Foundation (Grants No. 41240024, 41372285, 51161130523, 41272317, 41172251), the ANR-NSFC grant for the project RISMOGEO. In addition, the authors thank Dr. Jidong Zaho at Hong Kong University of Science and Technology for his strong support.

\section{References}

[1] K. Ishihara, Simple method of analysis for liquefaction of sand deposits during earthquakes, Soil Found. 17 (3) (1977) 1-17.

[2] S.L. Kramer, H.B. Seed, Initiation of soil liquefaction under static loading conditions, J. Geotech. Eng. 114 (4) (1988) 412-430.

[3] R. Verdugo, Characterization of sandy soil behavior under large deformation, PhD thesis, University of Tokyo, Tokyo, Japan, 1992.

[4] R.G. Wan, P.J. Guo, Effect of microstructure on undrained behaviour of sands, Can. Geotech. J. 38 (2001) 16-28.

[5] Z.Y. Yin, C.S. Chang, P.Y. Hicher, Micromechanical modelling for effect of inherent anisotropy on cyclic behaviour of sand, Int. J. Solids Struct. 47 (14-15) (2010) 1933-1951.

[6] C.S. Chang, Z.Y. Yin, Modeling stress-dilatancy for sand under compression and extension loading conditions, ASCE J. Eng. Mech. 136 (6) (2010) 777-786.

[7] C.S. Chang, Z.Y. Yin, Micromechanical modeling for behavior of silty sand with influence of fine content, Int. J. Solids Struct. 48 (19) (2011) $2655-2667$.

[8] Z.Y. Yin, C.S. Chang, Stress-dilatancy behavior for sand under loading and unloading conditions, Int. J. Numer. Anal. Methods Geomech. 37 (8) (2013) $855-870$.

[9] M. Belkhatir, A. Arab, T. Schanz, H. Missoum, N. Della, Laboratory study on the liquefaction resistance of sand-silt mixtures: effect of grading characteristics, Granul. Matter 13 (5) (2011) 599-609.

[10] R. Nova, Controllability of the incremental response of soil specimens subjected arbitrary loading programmes, J. Mech. Behav. Mater. 5 (2) (1994) 193-201.

[11] P.V. Lade, Static instability and liquefaction of loose fine sandy slopes, J. Geotech. Eng. ASCE 118 (1992) 51-71. 
[12] F. Darve, F. Laouafa, Instabilities in granular materials and application to landslides, Mech. Cohes.-Frict. Mater. 5 (8) (2000) 627-652.

[13] F. Nicot, F. Darve, H. Khoa, Bifurcation and second order-work in granular materials, Int. J. Numer. Anal. Methods Geomech. 31 (2007) $1007-1032$.

[14] A. Daouadji, F. Darve, H. Al Gali, P.Y. Hicher, F. Laouafa, S. Lignon, F. Nicot, R. Nova, M. Pinheiro, Diffuse failure in geomaterials: Experiments, theory and modeling, Int. J. Numer. Anal. Methods Geomech. 35 (16) (2011) 1731-1773.

[15] C.S. Chang, Z.Y. Yin, P.Y. Hicher, Micromechanical analysis for interparticle and assembly instability of sand, J. Eng. Mech. 137 (3) (2011) 155-168.

[16] J.F.W. Bishop, R. Hill, A theory of the plastic distortion of a polycrystalline aggregate under combined stresses, J. Philos. 42 (1951) $414-427$.

[17] R. Hill, A general theory of uniqueness and stability in elastic-plastic solids, J. Mech. Phys. Solids 6 (1958) $236-249$.

[18] P.V. Lade, D. Pradel, Instability and plastic flow of soils. I: Experimental observations, J. Eng. Mech. 116 (11) (1990) $2532-2550$.

[19] Yudhbir, R. Abedinzadeh, Quantification of particle shape and angularity using the image analyzer, Geotech. Test. J. 14 (3) (1991) $296-308$.

[20] J. Biarez, P.Y. Hicher, Elementary Mechanics of Soil Behaviours, Balkema, Rotterdam, The Netherlands, 1994.

[21] G. Cho, J. Dodds, J. Santamarina, Particle shape effects on packing density, stiffness, and strength: natural and crushed sands, J. Geotech. Geoenviron. Eng. 132 (5) (2006) 591-602.

[22] A.K. Ashmawy, B. Sukumaran, V.V. Hoang, Evaluating the influence of particle shape on liquefaction behaviour using discrete element modeling, in: Proc. 13th Int. Conf. on Offshore and Polar Engineering Conference Honolulu, Hawaii, USA, 2003, pp. 542-549.

[23] Cavarretta, The influence of particle characteristics on the engineering behaviour of granular materials, PhD thesis, Imperial College, London, 2009.

[24] ASTM D 4253, Standard test methods for maximum index density and unit weight of soils using a vibratory table.

[25] ASTM D 4254, Standard test methods for minimum index density, unit weight of soils, calculation of relative density.

[26] R. Verdugo, K. Ishihara, The steady state of sandy soils, J. Soil Found. 36 (2) (1996) 81-91.

[27] K. Ishihara, F. Tatsuoka, S. Yasua, Undrained deformation and liquefaction of sand under cyclic stresses, Soil Found. 15 (1) (1975) $29-44$.

[28] M.P. Luong, Stress-strain aspects of cohesionless soils under cyclic and transient loading, in: Proc. Int. Symp. on Soils under Cyclic and Transient Loading, Balkema, Rotterdam, The Netherlands, 1980, pp. 353-376.

[29] D. Muir Wood, K. Maeda, Changing grading of soil: effect on critical states, Acta Geotech. 3 (1) (2008) 3-14.

[30] W. Yan, J. Dong, Effect of particle grading on the response of an idealized granular assemblage, Int. J. Geomech. 11 (2011) $276-285$.

[31] C.O.R. Abbireddy, C.R.I. Clayton, Varying initial void ratios for DEM simulations, Geotechnique 60 (6) (2010) $497-502$.

[32] M. Cubrinovski, K. Ishihara, Maximum and minimum void ratio characteristics of sands, Soil Found. 42 (6) (2002) 65-78.

[33] T. Ng, Input parameters of discrete element methods, J. Eng. Mech. 132 (7) (2006) 723-729. 